SPLANCL, K. W. A theory of emotionatly based drive (D) and its relation to performance in simple learning situations. American Psychologist, 1958, 13, 131-141.

van KREVLLD, D., \& ZAJONC, R. B. The learning of influence structures. Journal of Personality, 1966, 34, 205-223

ZAJONC, R. B. Cognitive theories in social psychology. In G. Lindzey and E. Aronson (Eds.), Handbook of social psychology. (2nd ed.) Vol. 1. Reading. Mass: Addison-Wesley, 1968.

ZAJONC, R. B., \& BLRNSTEIN, E. Structural balance, reciprocity, and positivity as sources of cognitive bias. Journal of Personality, 1965, 33. $570-583$

NOTE

1. This rescarch was supported by Grant M4 164 from the National Institute of Mental Health.

\title{
Interpersonal attraction as a function of the accuracy of personal evaluations'
}

\section{JAY HEWITT, University of Victoria, Victoria, B.C., Canada}

Each $S$ was evaluated by four confederates. One evaluation was favorable and accurate, one was favorable and inaccurate, one was unfavorable and accurate, and one was unfavorable and inaccurate. After receiving these evaluations, the $S$ rated his attraction to each of the confederates. Attraction was greater when the evaluation was favorable than when it was unfavorable and attraction was greater when the evaluation was accurate than when it was inaccurate.

According to the cognitive consistency theory of interpersonal attraction, the attraction of one person (P) to another person $(\mathrm{O})$ is a function of the similarity between $O$ 's perception of $P$ and of P's perception of himself (Deutsch \& Solomon, 1959). Two major experimental designs can be employed to test this theory. In the first design, consistency is varied by manipulating the S's opinion of himself. Two groups of Ss are employed, one with a favorable opinion of themselves and one with an unfavorable opinion. Each $S$ is evaluated favorably or unfavorably by someone else. It is assumed that a favorable evaluation will be more consistent with the self-perception of someone with a high opinion of himself than with the self-perception of someone with a low opinion of himself. If this assumption is correct, people who receive a favorable evaluation should be more attracted to their evaluator if they have a high opinion of themselves than if they have a low opinion of themselves. It is also assumed that an unfavorable evaluation will be more consistent with the self-perception of someone with a low opinion of himself than with the self-perception of someone with a high opinion of himself. If this assumption is correct, people who receive an unfavorable evaluation should be more attracted to their evaluator if they have a low opinion of themselves than if they have a high opinion of themselves.

Support for the above predictions has been obtained when the evaluations concern the S's ability to succeed on a particular task (Deutsch \& Solomon, 1959). Consistency theory has not been supported when the evaluations concern the more enduring characteristics of the S's personality. Under these conditions, Ss with low self-esteem are more attracted to people who evaluate them favorably (Walster, 1965) and are more hostile to people who evaluate them unfavorably (Dittes, 1959) than are people with high self-esteem.

One problem with the first experimental design is that consistency is confounded with self-esteem. An evaluation that is consistent with the self-perception of someone with high self-esteem is inconsistent for someone with low self-esteem and vice versa. The failure of studies employing this design to support consistency theory may reflect not so much the inadequacy of consistency theory as the more powerful effects of self-esteem.

The purpose of the present study was to demonstrate that consistency theory does hold when the evaluations concern the more enduring characteristics of the S's personality. To avoid the problems of confounding consistency with self-esteem, an alternative experimental design was employed. In this design, consistency was manipulated by varying the content of the evaluations. The evaluation was either based on what the $S$ had previously said about himself (accurate evaluation) or was not based on this information (inaccurate evaluation). Regardless of whether the evaluation was favorable or unfavorable, it was predicted that the $S$ would be more attracted to his evaluator when the evaluation was accurate than when it was inaccurate.

\section{METHOD}

The Ss consisted of 12 male undergraduates recruited from an introductory psychology class. At each experimental session, two Ss were run simultaneously (although neither was aware of the other's presence).

Upon arriving for the experiment, the $S$ was seated in a small, soundproof cubicle and handed two lists of adjectives, one marked "desirable characteristics" and one marked "undesirable characteristics." On the first list, the $S$ was asked to put a checkmark beside the five words that best described his desirable characteristics and, on the second list, the five words that best described his undesirable characteristics. Each list contained 40 personality-trait adjectives (cf. Anderson, 1968), half of which were high in "desirability" (e.g., sincere, good-humored, intelligent) and half of which were low in "desirability" (e.g., antisocial, immature, self-centered).

After the $\mathrm{S}$ had described his desirable and undesirable characteristics, he was (erroneously) informed that there were four other people participating in the experiment, Ss A, B, C, and D. (In reality, A, $B, C$, and $D$ were confederates.) The $S$ was then handed a sheet which summarized the procedure. The sheet contained the following information. In the first phase of the experiment, the other participants (A, B, $C$, and D) would listen while E (the S) described himself. A, B, C, and D would then be asked to give their impression of $E$. Since all the rooms were equipped with intercoms, A, B, C, and D-would be able to hear E's self-description and $E$ would be able to listen while $A, B, C$, and $D$ gave their impression of him. (However, A, B, C, and D would not be able to hear one another's evaluation of $E$.) After the procedure had been explained, the $S$ was handed four identical lists of adjectives, informed that each evaluation would consist of three adjectives, and requested to put a checkmark beside the adjectives comprising each evaluation (the first list being used to record A's impression, the second list being used to record B's impression, etc.).

After the first $S$ had received the preliminary instructions, the procedure was repeated with the second $S$ (who was in a different room). The experimenter then retired to an adjoining room, taking with him the sheets on which the Ss had indicated their desirable and undesirable 
Table 1

Stean Attraction to Each of the Four Confederates as a Function of the Accuracy and Favorability of the Confederate's Evaluation of S

\begin{tabular}{lcr} 
& Accurate & Inaceurate \\
\hline Favorable & 4.24 & 3.33 \\
Unfavorable & 2.08 & -1.33 \\
\hline
\end{tabular}

characteristics. Any adjective that was checked by both Ss was deleted and, by a process of random elimination, the number of remaining checked adjectives on each sheet was reduced to three. (One pair of Ss had to be dismissed because the number of remaining adjectives numbered less than three.) Each list was then randomly assigned to one of the confederates.

After each confederate had been given his list of three adjectives (which would be his evaluation of $\mathrm{S} E$ ), the experimenter turned on the intercom and requested "S $E$ " to describe his goals in life, the kind of people he liked and disliked, his interests, and his personal problems. When both Ss were finished (they talked simultaneously), the experimenter asked $A, B, C$, and D (in that order) to give their impressions of $\mathrm{S} E$.

One evaluation consisted of three adjectives the first $S$ had employed to describe his desirable characteristics; one evaluation consisted of three adjectives the second $\mathrm{S}$ had employed to describe his desirable characteristics; one evaluation consisted of three adjectives the first $S$ had employed to describe his undesirable characteristics; and one evaluation consisted of three adjectives the second $S$ had employed to describe his undesirable characteristics. To the first $S$, these evaluations can be described as follows: favorable-accurate, favorable-inaccurate, unfavorable-accurate, and unfavorable-inaccurate. To the second $S$, the same cvaluations would be favorable-inaccurate, favorable-accurate, un favorable-inaccurate, and unfavorable-accurate.

After the four evaluations had been delivered, the Ss were asked to rate their attraction to each of the four confederates. A 21-point scale was employed, ranging in value from +10 (like very much) to -10 (dislike very much).

\section{RESULTS AND DISCUSSION}

A two-way (all within $\mathrm{Ss}$ ) analysis of variance was carried out on the data (Lindquist, 1953, pp. 237-238). The results suggested that people are attracted to those who evaluate them favorably and are attracted to those who evaluate them accurately. Attraction was greater when the evaluation was favorable than when it was unfavorable $(F=18.69 ; \mathrm{df}=1,11 ; \mathrm{p}<.01)$ and attraction was greater when the evaluation was accurate than when it was inaccurate $(\mathrm{F}=14.35 ; \mathrm{df}=1,11 ; \mathrm{p}<.01)$. The interaction between accuracy and favorability was not significant $(F=3.51$; $\mathrm{df}=1,11 ; \mathrm{p}>.05)$. The means are presented in Table 1 .

Prior support for consistency theory has been obtained when the evaluations concerned the S's ability to succeed on a particular task. The present study would seem to extend the generality of these findings by suggesting that consistency theory may hold when the evaluations concern the more enduring characteristics of the $S$ 's personality-the greater the accuracy, the greater the attraction.

Consistency theory would also seem to predict that a person would be more atiracted to someone giving him an accurate evaluation than to someone giving him a favorable evaluation. The results of the present study do not support this prediction. Six Ss were more attracted to the person delivering the favorable-inaccurate evaluation than to the person delivering the untavorable-accurate evaluation, three $\mathrm{Ss}$ showed the reverse pattern, and three Ss were equally attracted to both. Although the results will probably depend on the degree of accuracy and the degree of favorability, some doubt may be raised about the adequacy of consistency theory when accuracy and favorability are opposed to one another. The results of the present study do suggest, however, that consistency theory will be supported when favorability is held constant. ${ }^{2}$

\section{REFERENCES}

ANDERSON, N. H. Likableness ratings of 555 personality-trait words. Journal of Personality \& Social Psychology, 1968, 9, 272-279.

BERSCHEID, E., WALSTER, G. W., \& WALSTER, E. Effects of accuracy and positivity of an evaluation on liking for the evaluator. In E. Berscheid and E. Walster (Eds.), Interpersonal attraction. Reading, Mass.: Addison-Wesley, 1969

DEUTSCH, M., \& SOLOMON, L. Reactions to evaluations by others as influenced by self-evaluations. Sociometry, 1959, 22, 93-112.

DITTES, J. E. Attractiveness of group as a function of self-esteem and acceptance by group. Journal of Abnormal \& Social Psychology, 1959, 59, 77-82.

LINDQUIST, E. F. Design and analysis of experiments in psychology and education. Cambridge, Mass.: Hough ton-Mifflin, 1953.

WALSTER, E. The effect of self-esteem on romantic liking. Journal of Experimental Social Psychology, 1965, 1, 184-197. NOTES

1. This research was supported with a Faculty Research Grant from the University of Victoria.

2. As the manuscript was being submitted for publication it was learned that Berscheid, Walster. and Walster had completed a similar study and had achieved comparable results. 